\title{
Torque Analysis of Scotch Yoke Type Hydraulic Actuator
}

\author{
Sedong Kim ${ }^{1}$, Hee-Geun Song $^{1}$, Dae-Chul Lee ${ }^{3}$, Kwang-Bae Lee $^{3}$, Hyomin Jeong ${ }^{2}$ \\ ${ }^{1}$ Dept. of Energy and Mech. Eng., Graduate school, Gyeongsang National University, South Korea \\ ${ }^{2}$ Dept. of Energy and Mech. Eng., Institute of Marine Industry, Gyeongsang National University, Cheondaegukchi-Gil 38, Tongyeong, \\ 53064, South Korea \\ ${ }^{3} 9$, Hwajeonsandan 5-ro 98beo-gil, Gangseo-gu, Busan, South Korea
}

\begin{abstract}
At present, hydraulic actuators have been strongly highlighted in the shipbuilding industrial applications. The actuators are classified into three types according to their operation, such as scotch yoke, rack and pinion, rod and crank type. However, hydraulic actuators are more difficult than others electric motors because of nonlinear flow-pressure characteristics and many cases of torque between moving parts. In this paper, in order to obtain the data of the valve locking torque value of the scotch yoke, the pressure was applied at a pressure of 6 16 MPa and analysis by depending on cylinder diameter and yoke length using ANSYS tool. According to the results of generating torque value, it is understood that the torque increases as the cylinder diameter increases and the moment arm becomes longer. It can be also seen that the all average error rates of experimental values and program analysis values are only under the $3 \%$.
\end{abstract}

\section{Introduction}

Hydraulic actuators are not very common in high performance applications. However, especially hydraulic actuators are favorable due to their excellent rate of dimension to delivered torque. The hydraulic actuation system is applied marine system and shipbuilding industrial applications where high power density, high dynamic performance, robustness and overload capability are desired [1-3]. The motion of the controlled mechanism is generally generated by the direct torque control. These control motions are applied to the system for a dynamical model. To obtain excellent accuracy of control, the torque should be used precisely. Therefore, the actuators have torque characteristic, torques make to reduce the accuracy of the controlled motion. However, precise control of hydraulic actuators is more difficult than those of the conventional electric motors due to the presence of nonlinear flow-pressure characteristics, variations in the trapped fluid volume in each actuator chamber, fluid compressibility and the friction between moving parts; variations of hydraulic parameters, presence of leakage and transmission nonlinearities. In order to solve this problem, a various types of study are carried by many researchers [4-7]. Hydraulic actuators are classified into three types Rack\&Pinion type, ScotchYoke type, Rod\&Crank type [8-10]. Generally, Rack\&Pinion type which is simple in structure and affordable is preferred, and the, Scotch-Yoke type can be manufactured in a large size, and it is used for a valve of a large size. In this study, the torque analysis of the scotch yoke type was carried out. In order to get the basic data of the valve locking torque of the scotch yoke type, the pressure was applied at a pressure of $6 \sim 16 \mathrm{MPa}$ and investigated by depending on cylinder diameter and yoke length using ANSYS program.

\section{Numerical methods and model}

Figure 1 shows the scotch yoke type modelling and detailed analysis models which were middle type and End type when rotation is 45 degrees and 0 degree respectively that were shown in Figure 2 . There are 3 types of model ML400, ML600 and ML800. Detailed model sizes were shown in Table 1.
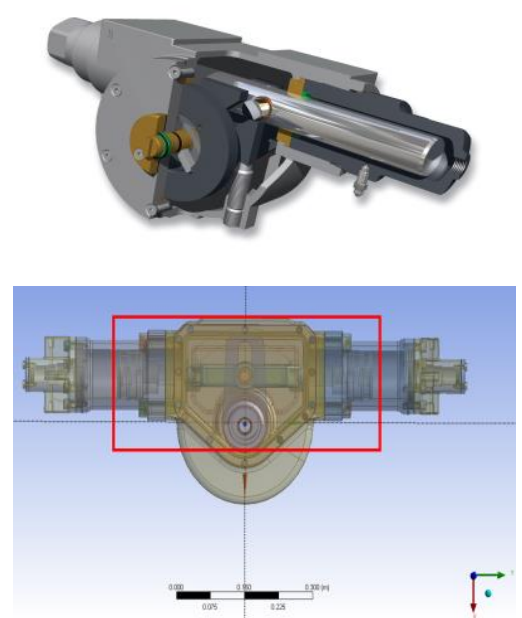

Fig. 1. Scotch Yoke Type Picture(Top) Modelling (bottom) 


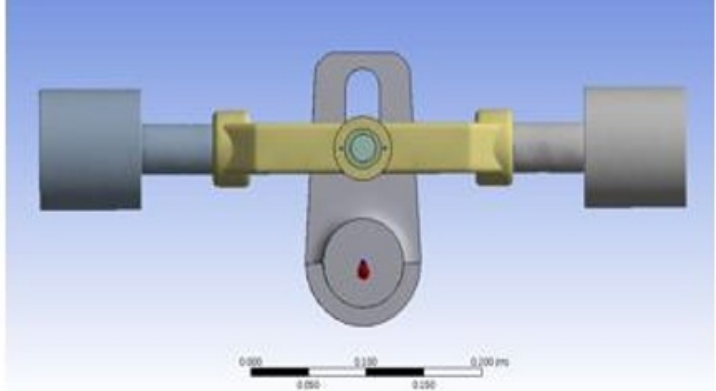

(a) Scotch-Yoke (middle)

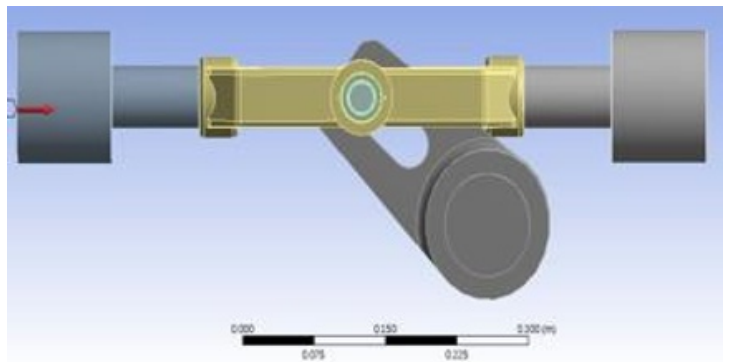

(b) Scotch-Yoke (end)

Fig. 2. Scotch Yoke Type Model - Middle type (a), End type (b)

Table 1. 3 types of Model detailed size.

\begin{tabular}{|l|l|l|l|}
\hline Type & ML400 & ML600 & ML800 \\
\hline Cylinder diameter & $9.5 \mathrm{~cm}$ & $11.5 \mathrm{~cm}$ & $14 \mathrm{~cm}$ \\
\hline $\begin{array}{l}\text { Middle type } \\
\text { (moment arm) }\end{array}$ & $0.09 \mathrm{~m}$ & $0.11 \mathrm{~m}$ & $0.135 \mathrm{~m}$ \\
\hline $\begin{array}{l}\text { End type } \\
\text { (moment arm) }\end{array}$ & $0.127 \mathrm{~m}$ & $0.1555 \mathrm{~m}$ & $0.19 \mathrm{~m}$ \\
\hline
\end{tabular}

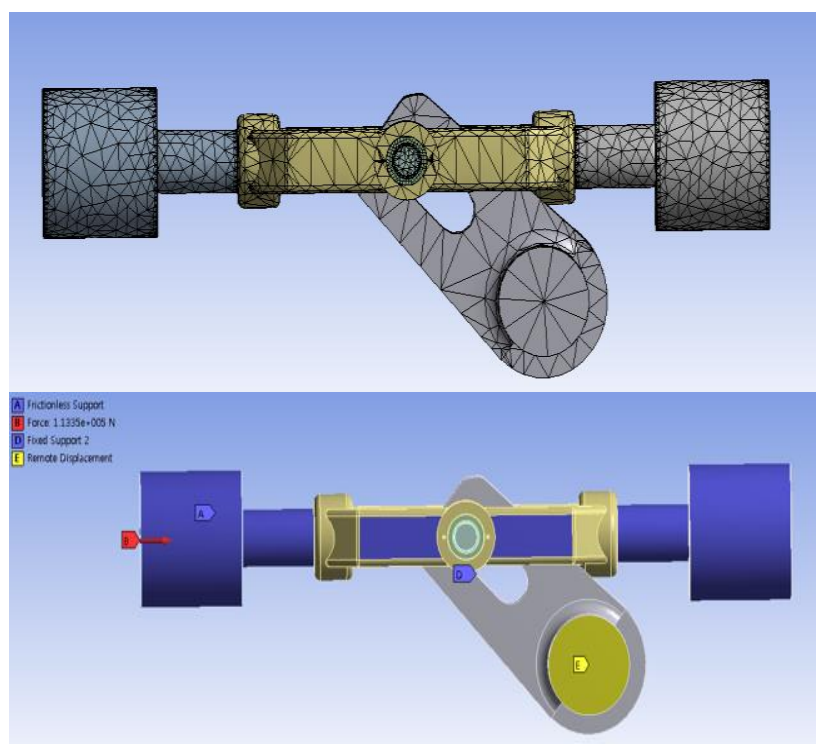

Fig. 3. Mesh for Scotch-Yoke Type Scotch (Top) Boundary conditions (bottom)

The analysis program was used for this research by ANSYS Ver 17.0 [11-12] using static method. Nodes for numerical analysis are 85,953 and Elements is 42,207 as shown in Fig 3. The contacts condition of Yoke and Pin was set to No separation. It was investigated each torque by operating pressure 6 16 MPa. Futhermore, properties of SCM440 were used for analysis were shown in Table 2.

Table 2. Material properties of SCM440.

\begin{tabular}{|l|l|}
\hline Properties & Value \\
\hline Density & $7861.1\left(\mathrm{~kg} / \mathrm{m}_{3}\right)$ \\
\hline Poisson's Ratio & 0.29 \\
\hline Young's Modulus & $211.3(\mathrm{GPa})$ \\
\hline Yield strength & $485(\mathrm{MPa})$ \\
\hline Tensile strength & $655(\mathrm{MPa})$ \\
\hline
\end{tabular}

\section{Result and Discussion}

This analysis was investigated for the generated torque values by ANSYS program, according to the each model. Fig 4-6 show the comparison of middle type and end type for each model.

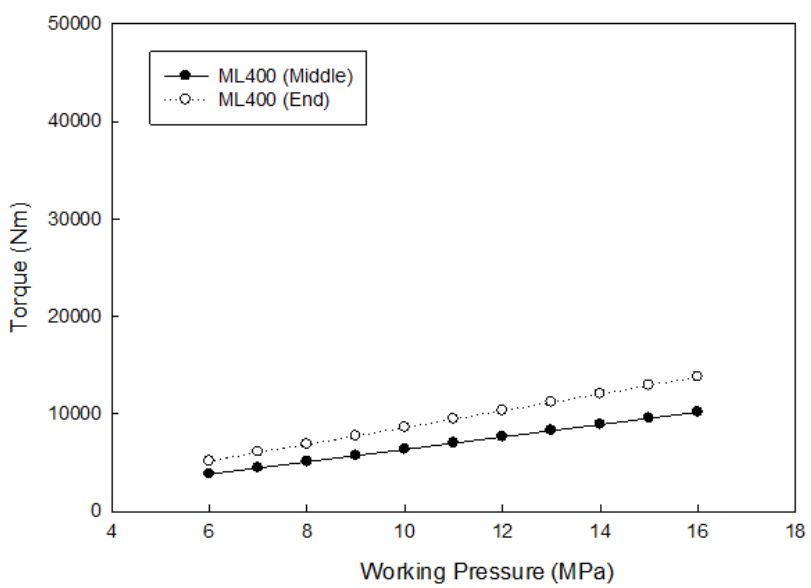

Fig. 4. Comparison of middle type and end type for ML400 model

As seen the Picture of ML400 model, it could be seen that the torque value at the end type has increased by $35 \%$ from the middle type. It shows that the torque value increases as the moment arm becomes longer.

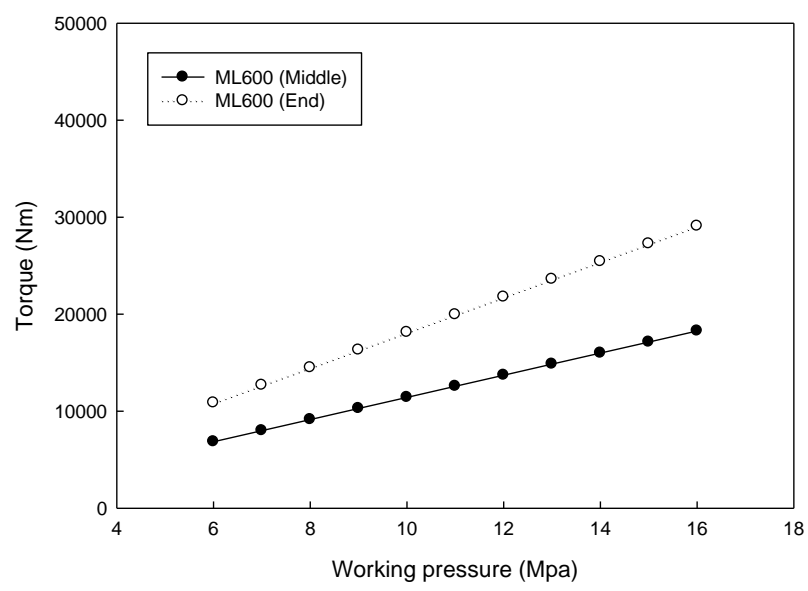

Fig. 5. Comparison of middle type and end type for ML600 model 
In case of the ML600, it shows that the torque value at the end type has increased by $60 \%$ from the middle type. It was revealed that the torque value increases as the moment arm becomes longer.

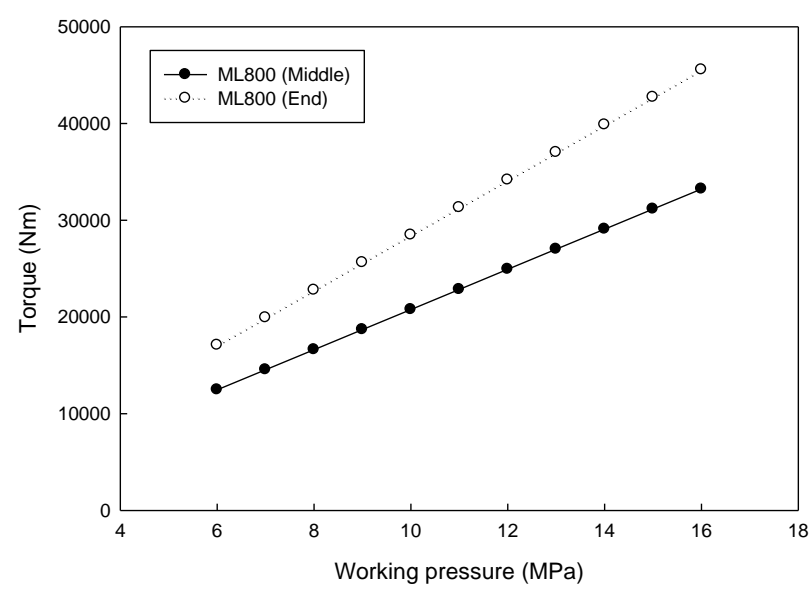

Fig. 6. Comparison of middle type and end type for ML800 model

In case of the ML800, it appears to be that the torque value at the end type has increased by $37 \%$ from the middle type.

In comparison the torque for two types of model, it is certain that the torque value of end type is clearly increased with moment arm compared to the middle type. In this regard, it was totally conformed that the torque value increases as the moment arm became longer.

In order to make sure of computational analysis was properly proceed, it was investigated to compare experimental data and program analysis data.

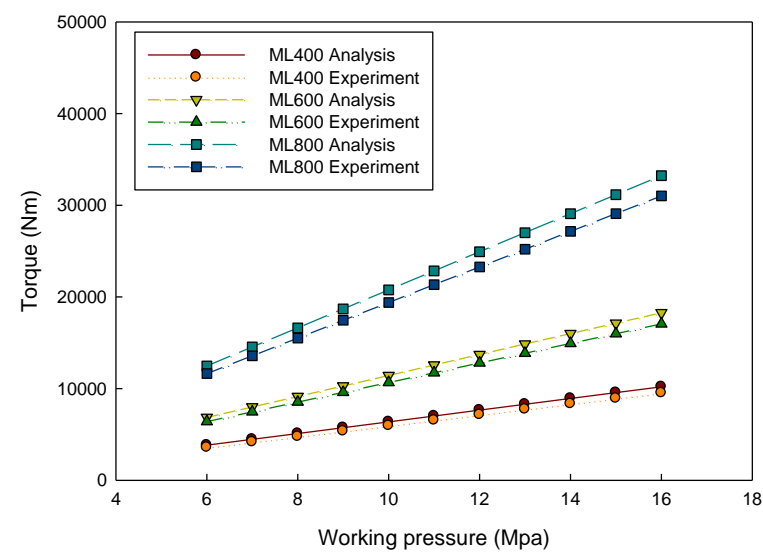

Fig. 7. Comparison with Experiment \& Analysis (Middle type)

Figure 7 shows that middle type of model for the experimental data and analysis data by each model ML400, ML600 and ML800. It can be seen that the average error rates of experimental values and program analysis values are $2.9 \%, 4.1 \%$ and $6.6 \%$ respectively. Figure 8 shows that comparison of experimental data to program analysis by each model ML400, ML600 and ML800. It is certain that average error rates of experimental values and program analysis values are only $1.2 \%, 2.7 \%$ and $6.1 \%$ respectively. Finally, it was proved that the ANSYS analysis result is properly conducted and it is certain that the torque value of end type and middle type are clearly increased with the cylinder diameter and moment arm.

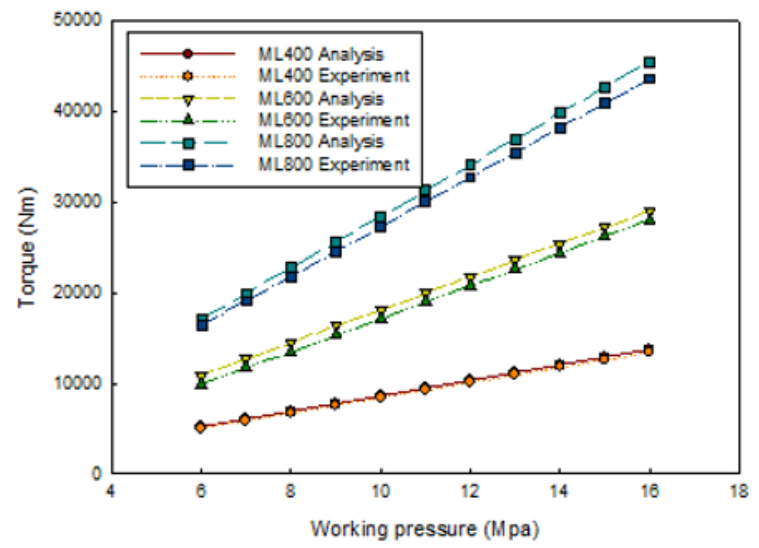

Fig. 8. Comparison with Experiment \& Analysis (End type)

\section{Conclusion}

With the consideration of highly important torque used in marine systems and shipbuilding industrial applications for operating, each model was analyzed to figure out how much torque generated. Models used in the study were three different cylinder size and moment arm size models. Experimental data were obtained by QRP tech, Co, south Korea before analyzing by ANSYS to make sure that the analysis is properly conducted. As seen the comparison of experimental data and analysis data of middle type of model by each model ML400, ML600, ML800, it can be confirmed that the average error rates of experimental values and program analysis value are $2.9 \%, 4.1 \%$ and $6.6 \%$ respectively. The comparison of experimental data to program analysis by each model ML 400, ML600, ML 800 also have very small error rates of that only $1.2 \%$, $2.7 \%, 6.1 \%$ respectively. In that regard, it was confirmed that the ANSYS analysis process is properly conducted and it is certain that the torque value of end type and middle type are clearly increased with the cylinder diameter and moment arm.

This research was supported by QRP (Quality Responsibility Partnership) tech co, South Korea and the National Research Foundation of Korea (NRF) funded by the Ministry of Science, ICT and future Planning (No. 2017R1A2B4007620).

\section{References}

[1] H. E. Merrit, Hydraulic control systems John Wiley \& Sons, New York (1967)

[2] R. B. Walters, Hydraulic and electro-hydraulic control systems Elsevier applied science (1991)

[3] J. Watton, Fluid Power Systems: Modeling, Simulation, Analog and Microcomputer Control, Prentice Hall, Hemel Hempstead, UK (1989)

[4] H. Du and N. D. Manring, A single-actuator control design for hydraulic variable displacement pumps, Proceedings of the American Control Conference, Arlington, pp. 4484-4489, June. (2001) 
[5] N. Niksefat and N. Sepehri, Designing robust force control of hydraulic actuators despite system and environmental uncertainties, IEEE Control Syst. Mag., 66-77, April (2001)

[6] L. Laval, N. K. M'Siridi, and J. C. Cadiou, H/sub /spl infin//-force control of a hydraulic servoactuator with environmental uncertainties, Proceedings of IEEE International Conference on Robotics and Automation, Minneapolis, MA, pp. 1566-1571, April (1996)

[7] H. Lu and W Lin, Robust controller with disturbance rejection for hydraulic servo systems, IEEE Transaction on Industrial Electronics, 40, 157-162, February (1993)

[8] G. A. Prattand M. M. Williamson, Series elastic actuators, in Proc. IEEE/RSJ Int. Conf. Intell. Robots Syst. Human Robot Interact. Cooperative Robots, vol. 1, pp. 399-406 (1995).

[9] D. W. Robinson, G. A. Pratt, Force controllable hydro-elastic actuator, Proceedings of the IEEE international Conference (2000)

[10] J. Pratt, B. Krupp, and C. Morse, Series elastic actuators for high fidelity force control, Ind. Robot, Int. J., vol. 29, no. 3, pp. 234-241 (2002)

[11]D. K. Kim, B. H. Kim, S. B. Shin, Development of Atomization Spraying System for Solvent-free Paint(I) - Flow Analysis of Hydraulic Actuator, The Korean Society of Manufacturing Process Engineers, vol. 10, No. 2, 61-66 (2011)

[12] S. K. Kim, D. K. Kim, Development of High Pressure Pump of 50MPa class for ship painting, Journal of Ocean Engineering and Technology, Vol.27, no.6, 106-111 (2013) 